Revue Française de Civilisation Britannique

BRITANNIQUE

French Journal of British Studies

XXIV-4 | 2019

Mutations politiques et économiques du Royaume-

Uni, entre perspective britannique et angle écossais

\title{
Pour saluer Jacques Leruez
}

In Homage to Jacques Leruez

Gérard Hocmard

(2) OpenEdition

Journals

Édition électronique

URL : http://journals.openedition.org/rfcb/4776

DOI : $10.4000 /$ rfcb.4776

ISSN : 2429-4373

Éditeur

CRECIB - Centre de recherche et d'études en civilisation britannique

Référence électronique

Gérard Hocmard, «Pour saluer Jacques Leruez », Revue Française de Civilisation Britannique [En ligne], XXIV-4 | 2019, mis en ligne le 25 novembre 2019, consulté le 27 novembre 2019. URL : http://

journals.openedition.org/rfcb/4776; DOI : 10.4000/rfcb.4776

Ce document a été généré automatiquement le 27 novembre 2019.

\section{(c) $($ ) $\odot$ (8Y NO}

Revue française de civilisation britannique est mis à disposition selon les termes de la licence Creative Commons Attribution - Pas d'Utilisation Commerciale - Pas de Modification 4.0 International. 


\title{
Pour saluer Jacques Leruez
}

\author{
In Homage to Jacques Leruez
}

\section{Gérard Hocmard}

1 C'est avec émotion que j'ai reçu cette invitation à rédiger un hommage à Jacques Leruez, dont j'ai partagé l'amitié pendant quarante ans.

2 Je l'ai connu par l'intermédiaire de Marie-Danièle, ma collègue à Paris III dans les années 1970. Jacques avait déjà à ce moment-là opéré le virage professionnel qui l'avait amené à quitter sa carrière de professeur certifié d'anglais pour reprendre des études, à la Faculté de Droit de Caen d'abord, puis à Paris à la Fondation nationale des Sciences politiques et à la Faculté de Droit. Il en était sorti avec un DEA, passant ainsi, comme l'a si joliment dit le Professeur Laidlaw dans l'hommage qu'il lui a rendu au nom de la Franco-Scottish Society, "d'angliciste à politologue, ou plutôt à politologue angliciste ». Détaché depuis quelques années au CNRS, il venait, lorsque j’ai fait sa connaissance, d'être inscrit sur la liste d'aptitude à la maîtrise et allait bientôt être nommé maître de recherches.

3 La sympathie mutuelle entretenue par des rencontres en Val de Loire orléanais chez une amie commune et par des centres d'intérêt partagés, en l'espèce les institutions et la vie politique britanniques, ont fait qu'à partir de ce moment-là nous avons eu des contacts fréquents en dépit de parcours très divergents. C'est ainsi que nous avons tous deux fait partie du petit noyau de happy few qui, autour de Monica Charlot, a fondé le CRECIB. Jacques a poursuivi une brillante carrière universitaire qui l'a amené à faire partie du Conseil de Laboratoire du CERI, puis représentant des chercheurs du CERI au Conseil scientifique de l'IEP de Paris avant de siéger au Comité national du CNRS, indépendamment de cours dispensés dans plusieurs universités parisiennes et de nombreuses directions de thèses. J'avais pour ma part choisi de continuer à enseigner en classes préparatoires. Nous nous retrouvions au sein du Conseil de Direction de l'Association France Grande-Bretagne, dont nous faisions partie tous deux, et aux séances de l'Association franco-écossaise, qu'il ne présidait pas encore mais dont il était déjà un des animateurs. 
Jacques avait à son actif une liste de publications impressionnante, qu'il s'agisse de livres ou d'articles. Son Royaume-Uni au XXe siècle, ses analyses du thatchérisme comme Thatcher, la Dame de fer ou Le Phénomène Thatcher, celles encore qu'il avait consacrées à l'Écosse : L'Écosse, une nation sans État ou, après la dévolution, L'Écosse, vieille nation, jeune État, avaient fait de lui un des analystes étrangers les plus écoutés en matière de vie politique britannique. Il avait à ce titre été demandé comme visiting professor par nombre d'universités du monde anglophone, invité comme intervenant dans de nombreux colloques internationaux, très sollicité par les radios hexagonales pour commenter les événements d'outre-Manche. La Reine en personne l'avait décoré, à titre honoraire, du titre de Commandeur de l'Ordre de l'Empire britannique.

Indépendamment des marches et randonnées qu'il effectuait avec zèle au sein d'un groupe portant le nom pittoresque de «Les Étapes savantes» ou de son jardin de La Cadière d'Azur qu'il cultivait avec amour, la passion de Jacques était l'Écosse. Il l'avait découverte en tant qu'assistant de français dans les années cinquante et y avait rencontré sa future épouse, Marie-Danièle. Devenu président de l'Association francoécossaise en 1997, il avait voué une grande partie de son énergie au développement, par l'intermédiaire de celle-ci, des relations d'amitié entre les deux pays de la «Vieille Alliance », organisant des programmes de conférences variés et attrayants, instituant le rite d'échanges annuels avec la Franco-Scottish Society et créant, avec l'aide de la Fondation catholique écossaise, un prix afin de récompenser chaque année le meilleur mémoire de recherche sur l'Écosse, dans le but de développer dans le monde universitaire l'intérêt pour celle-ci.

Plus que sa propre maladie, la mort de Marie-Danièle l'avait profondément affecté. Il n'était plus le même ensuite, dans les quelques mois qui ont précédé son propre décès, attentif cependant jusqu'au bout aux événements et soucieux du bon fonctionnement de l'Association franco-écossaise. Outre le chagrin qu'elle cause à ses proches et ses nombreux amis, français, écossais ou anglais, la disparition de Jacques Leruez crée un grand vide intellectuel à un moment où la situation confuse créée outre-Manche par le résultat du référendum sur le Brexit exigerait des commentateurs la profonde connaissance du monde britannique et la perspicacité qui étaient les siennes. Anglicistes, anglophiles, anglotropes, nous sommes tous en deuil et nous associons à celui de toute la famille aimante qui l'entourait.

\section{AUTEUR}

\section{GÉRARD HOCMARD}

Professeur de Première supérieure honoraire 